\title{
Lumbar Disc Herniation: Comparing Pain Relief After Medical and Surgical Intervention
}

FNU Abdullah ${ }^{1}$, Amerta Bai ${ }^{1}$, FNU Sahil ${ }^{2}$, Deepak Kataria ${ }^{3}$, Mohammed Abbas ${ }^{4}$, Farhan Ullah ${ }^{5}$, Sidra $\mathrm{Naz}^{6}$, Amna Jamil ${ }^{7}$, Aliya Fatima ${ }^{7}$, Sidra Memon ${ }^{8}$

1. Neurology, Jinnah Sindh Medical University, Karachi, PAK 2. Internal Medicine, Shaheed Mohtarma Benazir Bhutto Medical University, Larkana, PAK 3. Neurology, Shaheed Mohtarma Benazir Bhutto Medical University, Larkana, PAK 4. Internal Medicine, University of Louisville, Louisville, USA 5. Internal Medicine, Ayub Teaching Hospital, Karachi, PAK 6. Internal Medicine, University of Health Sciences, Lahore, PAK 7. Internal Medicine, Jinnah Postgraduate Medical Centre, Karachi, PAK 8. Internal Medicine, Jinnah Sindh Medical University, Karachi, PAK

Corresponding author: Sidra Memon, sidramemon311@gmail.com

\section{Abstract \\ Introduction}

The most common degenerative abnormality of the lumbar spine is lumbar disc herniation. There are two options of treatment, i.e. medical and surgical. Due to the scarcity of literature, it is a need of the hour to further study and evaluate the benefits and efficacy of early surgical intervention versus conservative management of lumbar disc herniation.

\section{Methods}

This study was conducted in the neurology unit of a tertiary care hospital in Pakistan from April 2019 to March 2021. After obtaining informed consent, 250 patients with a lumbar disc herniation, between the ages of 20 and 50 years, were enrolled in the study. Out of them, 81 participants chose surgical intervention while 169 participants chose medical intervention. Before the intervention, the patient's pain score was noted on the visual analog scale (VAS). The pain was assessed again 14 days after surgical intervention and 90 days after the start of medical intervention.

\section{Results}

There was a significant difference in the pain score in the post-intervention period in both the medical (7.01 \pm 1.05 vs. $3.54 \pm 0.51 ; p$-value: $<0.0001)$ and surgical intervention groups ( $6.92 \pm 0.95$ vs. $2.41 \pm 0.42 ; p$-value: $<0.0001)$. Post-intervention, the VAS pain score was significantly lower in the surgical group as compared to the medical group $(2.41 \pm 0.42$ vs. $3.54 \pm 0.51 ; \mathrm{p}$-value: $<0.0001)$.

\section{Conclusion}

Review began 06/09/2021 Review ended 06/14/2021 Published 06/24/2021

\section{๑) Copyright 2021}

Abdullah et al. This is an open access article distributed under the terms of the Creative Commons Attribution License CC-BY 4.0., which permits unrestricted use, distribution, and reproduction in any medium, provided the original author and source are credited.
In this study, there was a significant decline in pain in both groups; however, the reduction was more significant in the surgical group. Patients should be given both options for management of lumbar disc herniation and should be explained the pros and cons of each treatment option.

Categories: Internal Medicine, Neurology, General Surgery

Keywords: lumbar disc herniation, lumbar discectomy, medical management, pain management, degenerative lumbar disorders

\section{Introduction}

The most common degenerative abnormality of the lumbar spine is lumbar disc herniation. It is prevalent in $2 \%-3 \%$ of the world's population and mainly affects people in their fourth and fifth decades of life. It presents clinically as low back pain, followed by progressive sciatica. Its causes are multifactorial, including mechanical and genetic components. Smoking and repetitive mechanical loads and vibration play a major role as well [1]. It is usually diagnosed clinically while magnetic resonance imaging (MRI) is the diagnostic imaging of choice for lumbar disc herniation [2-3]. The management usually involves patient education, physical therapy, pharmacotherapy, and surgical intervention [4].

The objective of treatment is to relieve pain and help in neurological recovery with early return to daily work. Young patients with small disc herniation and mild neurological deficits are mainly treated conservatively [5]. Many advancements have been made in management recently. According to the recent clinical trials, it has been observed that recovery rate, as measured by the Japanese Orthopedic Association, is faster in the group with early surgery and favors an early return to work [6]. However, another research concludes that recovery by surgery takes longer, i.e. 11 weeks, whereas conservative treatment requires recovery in seven weeks [4]. 
Although a considerable amount of work has already been done globally, there is very limited data available in the local setting. Therefore, it is the need of the hour to further study and evaluate the benefits and efficacy of early surgical intervention versus conservative management of lumbar disc herniation.

\section{Materials And Methods}

This study was conducted in the neurology unit of a tertiary care hospital in Pakistan from April 2019 to March 2021. After obtaining informed consent, 250 patients with lumbar disc herniation of either gender, between the ages of 20 to 50 years, were enrolled in the study via consecutive convenient non-probability sampling. Lumbar disc herniation was confirmed by an MRI scan. Ethical review board approval was taken before the enrollment of participants.

After enrollment, patients' demographics and disc herniation location were noted in a self-structured questionnaire. Patients were counseled about the advantages and disadvantages of both medical and surgical treatment. Based on their preference, patients were enrolled in either the medical or the surgical intervention group. Surgical intervention was chosen by 81 participants while 169 participants chose medical intervention. Before the intervention, the patient's pain score was noted on the visual analog scale (VAS). The VAS has markings from zero to 10, where the former represents no pain and the latter represents worse pain.

Surgical intervention was done via minimally invasive lumbar discectomy 10 days after the enrollment of patients. The medical intervention included $75 \mathrm{mg}$ pregabalin thrice daily and painkillers, i.e. paracetamol $450 \mathrm{mg}$ and orphenadrine citrate $35 \mathrm{mg}$, each twice daily. The pain was assessed again 14 days after surgical intervention and 90 days after the start of medical intervention.

During the study, 11 participants requested surgical intervention and were excluded from the study; 24 patients were lost to follow-up, three in the surgical intervention group and 21 in the medical intervention group. More people were lost to follow-up in the medical intervention group, due to the longer period of follow-up. All participants that completed the follow-up were included in the final analysis.

Data were processed and analyzed using the Statistical Packages for Social Sciences (SPAA) version 23.0 (IBM Corp., Armonk, NY). The mean and standard deviation (SD) were calculated for continuous variables; frequencies and percentages were calculated for categorical variables. The mean pain score was compared using the t-test. A p-value of less than 0.05 meant that there is a difference between the two groups and the null hypothesis was void.

\section{Results}

No significant difference was found in the demographics and location of disc herniation between the medical and surgical intervention groups (Table 1).

\section{Demographics}

Age in years $($ Mean $\pm \mathrm{SD})$

Male

BMI more than $25 \mathrm{~kg} / \mathrm{m}^{2}$

Location of lumbar disc herniation

L4-L5

L5-S1
Medical intervention $(n=137)$

$39 \pm 6$

$70(51.0 \%)$

$38(27.7 \%)$

$101(73.7 \%)$

$36(26.3 \%)$
Surgical intervention $(n=78)$

$40 \pm 6$

$39(50.0 \%)$

$23(29.4 \%)$

$57(73.0 \%)$

$21(27.0 \%)$ p-value

NS

NS

NS

NS

TABLE 1: Comparison of demographics and location of disc herniation

BMI: body mass index

There was a significant difference in the VAS pain score in post-intervention period in both medical (7.01 \pm 1.05 vs. $3.54 \pm 0.51$; $p$-value: $<0.0001)$ and surgical intervention group (6.92 \pm 0.95 vs. $2.41 \pm 0.42$; $p$-value: $<0.0001)$. Post-intervention, the VAS pain score was significantly lower in the surgical as compared to the medical group ( $2.41 \pm 0.42$ vs. $3.54 \pm 0.51$; p-value: $<0.0001)$ (Table 2$)$. 


\section{Cureus}

\begin{tabular}{|c|c|c|c|c|}
\hline \multirow{2}{*}{ Group } & \multicolumn{2}{|c|}{ VAS Score (Mean \pm SD) } & \multicolumn{2}{|l|}{ p-value } \\
\hline & Pre-intervention & Post-intervention & Intragroup ${ }^{*}$ & Intergroup ${ }^{\star *}$ \\
\hline Medical & $7.01 \pm 1.05$ & $3.54 \pm 0.51$ & $<0.0001$ & \multirow{2}{*}{$<0.0001$} \\
\hline Surgical & $6.92 \pm 0.95$ & $2.41 \pm 0.42$ & $<0.0001$ & \\
\hline \multicolumn{5}{|c|}{$\begin{array}{l}\text { TABLE 2: Comparison of pre-and post-intervention VAS score in both groups } \\
\text { *calculated by comparing pre and post-intervention VAS score within the same group }\end{array}$} \\
\hline \multicolumn{5}{|c|}{${ }^{* *}$ calculated by comparing the post-intervention score of both groups } \\
\hline VAS: visual & scale & & & \\
\hline
\end{tabular}

\section{Discussion}

The results of our study demonstrated that there was a significant difference in VAS pain score in the postintervention period in both the medical and surgical groups. Moreover, the post-intervention VAS pain score was found to be significantly lower in the surgical group as compared to the medical group. The results of our study are in line with other studies. In a randomized controlled trial (RCT), early surgery for sciatica that had lasted for six to 12 weeks was compared with prolonged conservative care for six months. The trial showed rapid pain relief after early surgery in comparison to prolonged conservative care [7]. Similarly, Nygaard et al. and Ng et al. also highlighted that delayed surgery after eight to 12 months of sciatica showed worse results than earlier surgery [8-9]. Moreover, some of the high-quality observational cohort series showed significantly worse results after prolonged conservative care compared with surgery [10].

One of the major advantages in previous studies of early surgery for patients is faster relief of leg pain, reassurance, and earlier return to daily activities of life. However, these advantages of surgery by six months follow-up and even at eight weeks were no longer significant among them. Most of the patients also faced discomfort because of delayed surgery, whereas up to $56 \%$ of the patients recovered without any surgery [11]. In previous studies, it was found that better symptoms, functional status, and reassurance were associated with surgical treatment but no significance on disability or work outcomes was observed at five years. However, disability or work outcomes, combined with many factors, are more likely related to medical treatment. These factors may include accommodations in the workplace, tasks, autonomy, satisfaction, other sources of income, local economic factors, etc. [12]. This indicated that patients who were treated surgically showed greater relief from symptoms and improvement in the functional status upon follow-up as compared with patients who had non-surgical treatment [13]. Most of the patients prefer conservative treatment due to the lower risk of complications but rapid pain relief is more associated with surgical treatment. Previous observational studies have also found rapid back pain reduction with surgical treatment [14-15]. Previous RCTs have also demonstrated rapid pain reduction in patients who received surgery, but no significant benefit of surgery over conservative treatment at long-term assessments of neurogenic symptoms was observed $[7,16]$.

The study has its limitations. First, since it was conducted in a single institute, care should be taken while inferring the result to a larger group and the sample size may have not been very diverse. Second, only pain was measured as an outcome of medical and surgical intervention.

\section{Conclusions}

In this study, there was a significant reduction in pain in both groups; however, the reduction was more significant in the surgical group. Patients should be given both options for the management of lumbar disc herniation and should be explained the pros and cons of each treatment option. Further large-scale studies are needed to assess the long-term impact of surgical and medical intervention.

\section{Additional Information}

\section{Disclosures}

Human subjects: Consent was obtained or waived by all participants in this study. Jinnah Sindh Medical University issued approval JSMU/IRB-Ofc/2019-04-03. Animal subjects: All authors have confirmed that this study did not involve animal subjects or tissue. Conflicts of interest: In compliance with the ICMJE uniform disclosure form, all authors declare the following: Payment/services info: All authors have declared that no financial support was received from any organization for the submitted work. Financial relationships: All authors have declared that they have no financial relationships at present or within the previous three years with any organizations that might have an interest in the submitted work. Other 
relationships: All authors have declared that there are no other relationships or activities that could appear to have influenced the submitted work.

\section{References}

1. Vialle LR, Vialle EN, Suárez Henao JE, Giraldo G: Lumbar disc herniation. Rev Bras Ortop. 2010, 45:17-22. 10.1016/S2255-4971(15)30211-1

2. Modic MT, Ross JS, Obuchowski NA, Browning KH, Cianflocco AJ, Mazanec DJ: Contrast-enhanced MR imaging in acute lumbar radiculopathy: a pilot study of the natural history. Radiology. 1995, 195:429-35. 10.1148/radiology.195.2.7724762

3. Jackson RP, Cain JE Jr, Jacobs RR, Cooper BR, McManus GE: The neuroradiographic diagnosis of lumbar herniated nucleus pulposus: II. A comparison of computed tomography (CT), myelography, CTmyelography, and magnetic resonance imaging. Spine (Phila Pa 1976). 1989, 14:1362-7. 10.1097/00007632198912000-00013

4. Awad JN, Moskovich R: Lumbar disc herniations. Surgical versus nonsurgical treatment. Clin Orthop Relat Res. 2006, 443:183-97. 10.1097/01.blo.0000198724.54891.3a

5. Leonardi M, Boos N: Disc herniation and radiculopathy. Spinal Disorders. Aebi M (ed): Springer, Berlin, Heidelberg; 2009. 481-512. 10.1007/978-3-540-69091-7_18

6. van den Hout WB, Peul WC, Koes BW, Brand R, Kievit J, Thomeer RT: Prolonged conservative care versus early surgery in patients with sciatica from lumbar disc herniation: cost utility analysis alongside a randomised controlled trial. BMJ. 2008, 336:1351-4. 10.1136/bmj.39583.709074.BE

7. Peul WC, van Houwelingen HC, van den Hout WB, et al.: Surgery versus prolonged conservative treatment for sciatica. N Engl J Med. 2007, 356:2245-56. 10.1056/NEJMoa064039

8. Nygaard OP, Kloster R, Solberg T: Duration of leg pain as a predictor of outcome after surgery for lumbar disc herniation: a prospective cohort study with 1-year follow up. J Neurosurg. 2000, 92:131-4. 10.3171/spi.2000.92.2.0131

9. Ng LC, Sell P: Predictive value of the duration of sciatica for lumbar discectomy. A prospective cohort study . J Bone Joint Surg Br. 2004, 86:546-9.

10. Rothoerl RD, Woertgen C, Brawanski A: When should conservative treatment for lumbar disc herniation be ceased and surgery considered?. Neurosurg Rev. 2002, 25:162-5. 10.1007/s101430100184

11. Peul WC, van den Hout WB, Brand R, Thomeer RT, Koes BW: Prolonged conservative care versus early surgery in patients with sciatica caused by lumbar disc herniation: two year results of a randomised controlled trial. BMJ. 2008, 336:1355-8. 10.1136/bmj.a143

12. Atlas SJ, Keller RB, Chang Y, Deyo RA, Singer DE: Surgical and nonsurgical management of sciatica secondary to a lumbar disc herniation. Five-year outcomes from the Maine Lumbar Spine Study. Spine (Phila Pa 1976). 2001, 26:1179-87. 10.1097/00007632-200105150-00017

13. Atlas SJ, Chang Y, Kammann E, Keller RB, Deyo RA, Singer DE: Long-term disability and return to work among patients who have a herniated lumbar disc: the effect of disability compensation. J Bone Joint Surg Am. 2000, 82:4-15. 10.2106/00004623-200001000-00002

14. Weinstein JN, Lurie JD, Tosteson TD, et al.: Surgical vs nonoperative treatment for lumbar disk herniation. The Spine Patient Outcomes Research Trial (SPORT) observational cohort. JAMA. 2006, 296:2451-9. 10.1001/jama.296.20.2451

15. Atlas SJ, Keller RB, Wu YA, Deyo RA, Singer DE: Long-term outcomes of surgical and nonsurgical management of sciatica secondary to a lumbar disc herniation: 10 year results from the Maine Lumbar Spine Study. Spine (Phila Pa 1976). 2005, 30:927-35. 10.1097/01.brs.0000158954.68522.2a

16. Weinstein JN, Tosteson TD, Lurie JD, et al.: Surgical vs nonoperative treatment for lumbar disk herniation. The Spine Patient Outcomes Research Trial (SPORT): a randomized trial. JAMA. 2006, 296:2441-50. 10.1001/jama.296.20.2441 